Парута Валентин Анатольевич, канА. техн. наук, доцент, доцент кафедры процессов и аппаратов в технологии строительных материалов, Одесская государственная академия строительства и архитектуры (г. ОАесса, Украина)

Гнып Ольга Павловна, канд. техн. наук, доцент, доцент кафедры процессов и аппаратов в технологии строительных материалов, ОАесская государственная академия строительства и архитектуры (г. ОАесса, Украина)

Лавренюк Меонид Иванович, канд. техн. наук, доцент, доцент кафедры процессов и аппаратов в технологии строительных материалов, Одесская государственная академия строительства и архитектуры (г. ОАесса, Украина)

Бачинский Вячеслав Васильевич, канд. техн. наук, Аоцент, Аоцент кафелры процессов и аппаратов в технологии строительных материалов, ОАесская государственная академия строительства и архитектуры (г. ОАесса, Украина)

Гринева Ирина Ивановна, канА. техн. наук, ассистент кафедры железобетонных конструкций и транспортных сооружений, ОАесская государственная академия строительства и архитектуры (г. ОАесса, Украина)

\title{
НАУЧНЫЕ ОСНОВЫ ПРОЕКТИРОВАНИЯ СОСТАВОВ ШТУКАТУРНЫХ РАСТВОРОВ
}

(C) РУП “Институт БелНИИС", 2019

Institute BeINIIS RUE, 2019

\section{АННОТАЦИЯ}

Увеличение объемов высотного строительства, применение новых стеновых материалов требует переосмысления подхода $\kappa$ проектированию составов штукатурных растворов. Это вызвано тем, что нагрузки на штукатурное покрытие, находящееся на 1 или 24 этажах здания, значительно отличаются.

Решить поставленную задачу в рамках существующих представлений, принципов и нормативных требований невозможно, 
так как они применимы для растворов, применяемых при малоэтажном строительстве.

Для достижения поставленной цели в данной статье разработана научная основа проектирования составов штукатурных растворов для высотных зданий. А для әтого проведен анализ процессов, протекающих в штукатурном покрытии при его нанесении и твердении, механизма разрушения системы «кладка - штукатурное покрытие». Выявлены и проанализированы на примерах и графиках основные причины развития трещин, такие как температурные и влажностные деформации штукатурного покрытия и кладки и их разность, напряжения, вызванные ими, воздействие влаги, льда и агрессивных веществ. Для того чтобы предотвратить разрушение штукатурного покрытия, рассчитали величины физико-механических характеристик (прочность при сжатии и изгибе, модуль упругости и др.), с учетом напряжений в нем и контактной зоне с кладкой, возникающие при твердении раствора и деформации стеновой конструкции. Сформулированы принципы и критерии, при которых будет обеспечена долговечность штукатурного покрытия и стеновой конструкции. Рекомендованы составляющие и подобраны два состава раствора, которые позволили увеличить водоудерживаюшую способность смеси, уменьшить усадку штукатурного покрытия при твердении, уменьшить количество трещин, возникающих при твердении, и предотвратить или замедлить их развитие.

Ключевые слова: штукатурные растворы, высотное строительство, твердение раствора, состав штукатурного раствора, трещины в растворе.

Для цитирования: Парута, В. А. Научные основы проектирования составов штукатурных растворов / В. А. Парута, О. П. Гнып, Л. И. Лавренюк, В. В. Бачинский, И. И. Гринева // Проблемы современного бетона и железобетона : сб. науч. тр. / Ин-т БелНИИС; редкол.: О. Н. Лешкевич [и др.]. - Минск, 2019. - Вып. 11. - С. 205218. https://doi.org/10.35579/2076-6033-2019-11-13 
Valentin Paruta, PhD in Engineering Science, Associate Professor, Odessa State Academy of Civil Engineering and Architecture (Odessa, Ukraine)

Olga Gnyp, PhD in Engineering Science, Associate Professor, Odessa State Academy of Civil Engineering and Architecture (Odessa, Ukraine)

Leonid Lavrenyuk, PhD in Engineering Science, Associate Professor, Odessa State Academy of Civil Engineering and Architecture (Odessa, Ukraine)

Vyacheslav Bachinsky, PhD in Engineering Science, Associate Professor, Odessa State Academy of Civil Engineering and Architecture (Odessa, Ukraine)

Iryna Grynyova, $\mathrm{PhD}$ in Engineering Science, Assistant, Odessa State Academy of Civil Engineering and Architecture (Odessa, Ukraine)

\section{SCIENTIFIC BASIS OF DESIGN STRUCTURES PLASTER SOLUTIONS}

\section{ABSTRACT}

The increase the volume of the high-rise construction, the use of new wall materials, requires a rethinking of the approach to the design of plaster mortar compositions. This is due to the fact that the load on the plaster coating, located on the 1 or 24 floors of the building, are significantly different.

To solve the problem within the framework of existing concepts, principles and regulatory requirements is not possible, as they are applicable to solutions used in low-rise construction.

To achieve this goal, the scientific basis for the design of plaster mortar compositions for high-rise buildings was developed in this article. An analysis of the processes occurring in the plaster coating during its application and hardening, the destruction mechanism of the system "masonry - plaster coating" was carried out. The main reasons for the development of cracks, such as temperature and moisture deformations of the plaster coating and masonry and their difference, the stresses caused by them, exposure to moisture, ice and aggressive substances, were identified and analyzed using examples and graphs. In order to prevent the destruction of the plaster coating, the values of physical and mechanical characteristics (compressive 
and bending strength, elastic modulus, etc.) were calculated, taking into account the stresses in it and the contact zone with the masonry, arising from the hardening of the mortar and the deformation of the wall structure. The principles and criteria are formulated under which the durability of the plaster coating and wall structure will be ensured. For two compositions of the mortar, which allowed to increase the water-holding ability of the mixture, reduce the shrinkage of the plaster coating during hardening, reduce the number of cracks that occur during hardening and prevent or slow down their development, the components were recommended and selected.

Keywords: plaster mortars, high-rise construction, hardening of mortar, composition of plaster mortar, cracks in the mortar.

For citation: Paruta V., Gnyp O., Lavrenyuk L., Bachinsky V., Grynyova I. Scientific basis of design structures plaster solutions. Contemporary Issues of Concrete and Reinforced Concrete: Collected Research Papers. Minsk. Institute BelNIIS. Vol. 11. 2019. pp. 205-218. https://doi.org/10.35579/2076-6033-2019-11-13 (in Russian)

\section{BВEAЕНИЕ}

Увеличение доли высотного строительства и широкое применение новых стеновых материалов требуют переосмысления подхода к проектированию составов штукатурных растворов. Это обусловлено тем, что воздействия и нагрузки на штукатурное покрытие, находящееся на 24 этаже здания, значительно отличаются от тех, которые оно испытывает на 1-3 этажах (рис. 1).

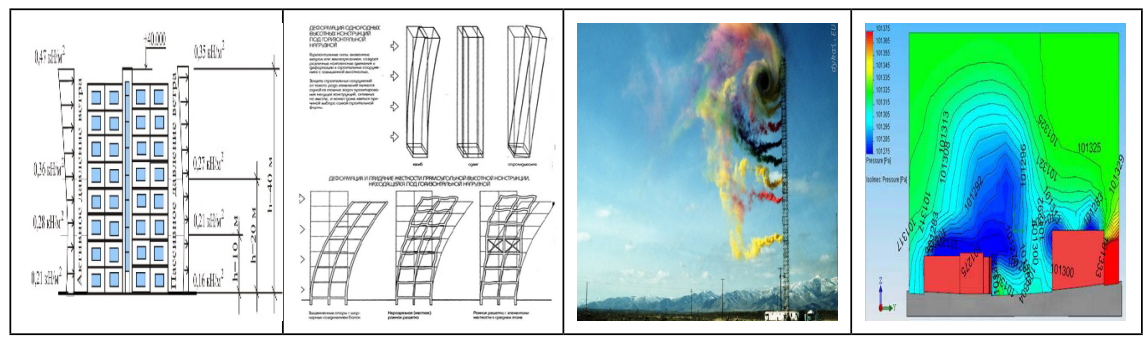

Рисунок 1. Изменение воздействий и нагрузок на штукатурное покрытие при увеличении высотности зАания 
Необходимо учитывать и то, что при возведении высотных зданий на территории Украины в основном используют автоклавный газобетон со средней плотностью 150-600 кг/м ${ }^{3}$. Его свойства (прочность при сжатии, модуль упругости, температурные деформации) зависят от средней плотности и значительно отличаются от свойств традиционных стеновых материалов (кирпича керамического и силикатного, блоков из легкого бетона и горных пород).

Решить поставленную задачу в рамках существующих представлений и принципов невозможно. Они применимы для растворов, эксплуатируемых в малоэтажном строительстве. Нормативные требования, предъявляемые к штукатурным растворам для стен из автоклавного газобетона, также этого не учитывают, они противоречивы и, по нашему мнению, не обоснованы. Так, например, прочность при сжатии должна составлять 1,5-7,5 МПа (Россия), 2,5 МПа (Украина) и 10 МПа (Германия). Прочность на изгиб должна составлять 1-1,25 МПа (Украина) и 2 МПа (Россия). Величина адгезии к газобетонной кладке должна составлять 0,15-3 МПа (Россия) и 0,5 МПА (Украина).

\section{ПОСТАНОВКА ЗАААЧИ}

Для достижения требуемых целей требуется разработка новых научных основ проектирования составов штукатурных растворов. Необходим анализ процессов, протекающих в штукатурном покрытии при его нанесении и твердении, знание механизма разрушения системы «кладка - штукатурное покрытие», расчет и учет напряжений.

Долговечность стеновой конструкции в значительной мере зависит от количества дефектов в штукатурном покрытии и контактной зоне между ним и кладкой. Разрушение системы «кладка - штукатурное покрытие» обусловлено накоплением и развитием микро- и макротрещин в ней. Для оценки ресурса работы такой системы необходимо определение внутренних и внешних факторов, степень их воздействия, расчет напряженного состояния, знание процессов зарождения, накопления повреждений и роста макротрещин. Назначенные физико-механические параметры и 
составы штукатурных растворов должны обеспечить «работу» системы при максимальном уровне таких напряжений.

\section{ОСНОВНОЙ МАТЕРИАА И РЕЗУАЬТАТЫ}

Кладка из автоклавного газобетона обладает высоким капиллярным потенциалом из-за значительного объема пор (520 мм ${ }^{3} /$ г) и их высокой удельной поверхности (22-34 $\mathrm{m}^{2} /$ г) [1]. При нанесении растворной смеси на кладку из-за ее низкой водоудерживающей способности происходит отсасывание жидкости из нее лиофильными порами и капиллярами материала кладки (рис. 2а). Скорость заполнения поры (v) определяется уравнением Пуазейля:

$$
v=-\frac{r^{2}}{8 \eta} \cdot \frac{\Delta p}{l}
$$

где $l$ - длина участка впитавшейся жидкости, $\eta$ - ее вязкость, $\Delta p$ - перепад давления на участке $l$, равный капиллярному давлению мениска:

$$
\Delta p=-2 s_{12} \cos q / r .
$$

Поэтому растворение цемента и образование пересыщенного раствора происходит при пониженном содержании воды. Из-за этого происходит неполная гидратация цемента, образуются неравновесные, метастабильные новообразования типа:

$$
\begin{gathered}
1,83 \cdot\left(3 \mathrm{CaO} \cdot \mathrm{Al}_{2} \mathrm{O}_{3}\right)+1,48 \cdot\left(\mathrm{CaSO}_{4} \cdot 2 \mathrm{H}_{2} \mathrm{O}\right)+3,38 \cdot \mathrm{Ca}(\mathrm{OH})_{2}+16,67 \cdot \mathrm{H}_{2} \mathrm{O} \\
\rightarrow 0,42 \cdot\left(3 \mathrm{CaO} \cdot \mathrm{Al}_{2} \mathrm{O}_{3} \cdot 6 \mathrm{H} 2 \mathrm{O}\right)+1,42 \cdot\left(3 \mathrm{CaO} \cdot \mathrm{Al}_{2} \mathrm{O}_{3} \cdot \mathrm{CaSO}_{4} \cdot 12 \mathrm{H}_{2} \mathrm{O}\right)+ \\
+3,38 \cdot \mathrm{Ca}(\mathrm{OH})_{2}+0,07 \cdot \mathrm{CaSO}_{4} \cdot 2 \mathrm{H}_{2} \mathrm{O} .
\end{gathered}
$$

Потеря воды приводит к усадке штукатурного раствора 2,5...5,8 мм/м [2]. А так как газобетонная кладка «сдерживает» эти деформации, то это приводит к возникновению напряжений в нем $(\delta)$, которые в семь раз превышают его предел прочности при растяжении:

$$
\delta=\frac{\Delta \varepsilon^{*} \cdot E}{1-\mu}
$$

где Е и $\mu$ - модуль упругости и коэффициента Пуассона штукатурного покрытия; - разность деформаций штукатурки и газобетонного основания [3]. 
Из-за этих напряжений и из-за того, что уменьшение степени гидратации цемента привело к снижению предельной растяжимости материала (на 20...50 \%) [4, 5, 6], происходит образование трещин в штукатурном покрытии (на поверхности и в объеме материала), а также в контактной зоне с кладкой (рис. 2в, 2г, 2д).

При эксплуатации они «развиваются» и объединяются в магистральные. Причинами развития трещин являются температурные и влажностные деформации штукатурного покрытия и кладки [6,7] и их разность (рис. 3в, 3д), напряжения, вызванные ими (рис. 3г), воздействия влаги, льда и агрессивных веществ.

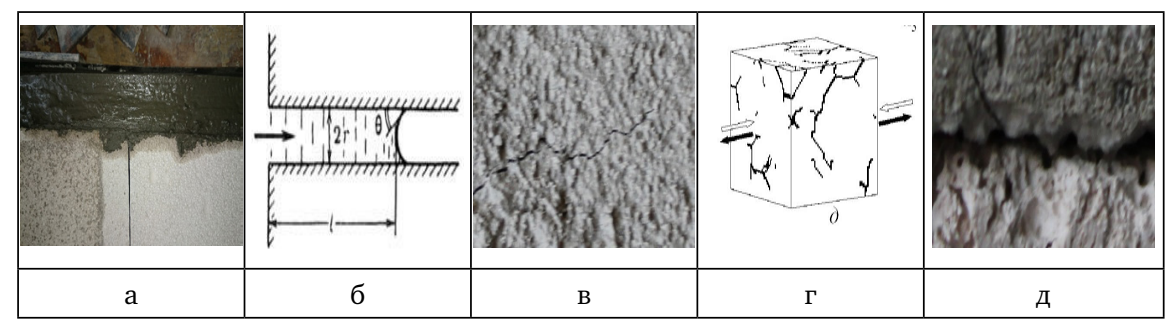

Рисунок 2. Трещинообразование в штукатурном покрытии и контактной зоне межАу ним

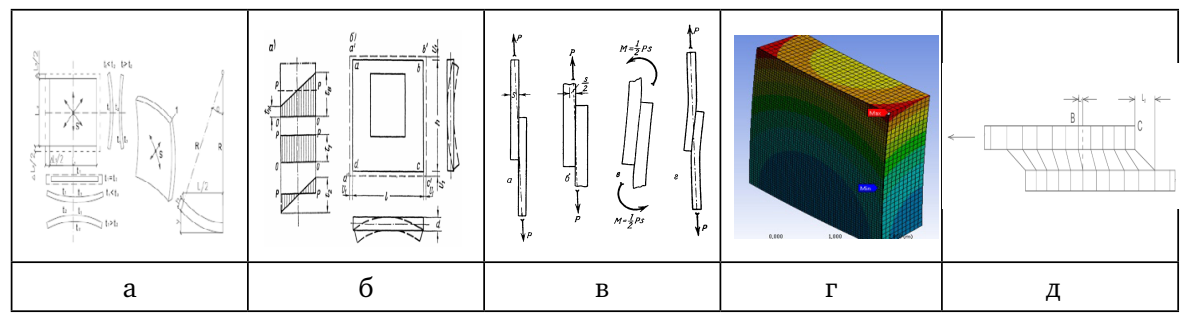

Рисунок 3. Температурные и влажностные деформации кладки (а, б) и напряжения в ней (г)

Циклические температурно-влажностные воздействия приводят к деформации (3), (6), (8) и дополнительным напряжениям в штукатурном покрытии $(\delta)(3)$, которые являются причиной развития целого семейства магистральных трещин.

$$
\begin{aligned}
& \Delta L_{p}=\alpha \cdot \Delta T^{p} \cdot L \\
& \Delta L_{C}=\alpha \cdot \Delta T^{C} \cdot L
\end{aligned}
$$




$$
\Delta L_{\mathrm{тв}}=\left(\alpha \cdot \Delta L \cdot T \cdot F_{m}\right)+\left(\Delta L_{q} \cdot L\right)
$$

где $\Delta L_{p}, \Delta L_{C}-$ деформации растяжения и сжатия; $\alpha-$ коэффициент температурного удлинения материала; $\Delta T^{p}, \Delta T^{C_{-}}$разность температур; L - длина стенового элемента; $\Delta L_{\text {тв }}$ - тепловлажностные деформации; $F_{m}$ - показатель материальных дефектов; влажностные деформации [3].

$$
\begin{gathered}
\delta=\kappa \cdot \sqrt{\left[\alpha_{t}+b(L-c)\right] \cdot \delta^{*}} \\
\delta^{*}=E \cdot \alpha_{t} \cdot \Delta t
\end{gathered}
$$

где Е-модуль упругости; $\alpha_{t}-$ коэффициент линейного расширения штукатурного покрытия; $\Delta t$ - расчетный перепад температур;

Кладка и штукатурное покрытие имеют разные по величине температурные деформации. Величину этих деформаций определяют из выражения [6]:

$$
\begin{aligned}
& \Delta L=L_{0} \cdot \alpha_{t} \cdot \Delta t, \\
& \Delta t=t_{2}-t_{1},
\end{aligned}
$$

где $\Delta L$ - относительное удлинение или сокращение стеновой конструкции; $L_{0}$ - длина стеновой конструкции на момент возведения; $\alpha_{t}$ - коэффициент температурного расширения автоклавного газобетона и штукатурного покрытия $[1,6], \Delta t-$ изменение температуры стеновой конструкции;

$t_{1}$ - температура окружающей среды в момент возведения газобетонной кладки и нанесения штукатурного покрытия; $t_{2}-$ максимальная и минимальная температура, воздействию которой подвергается стеновая конструкция в летний и зимний периоды;

Зимой, при $-20^{\circ} \mathrm{C}$, для кладки длиной 8 м, выполненной летом при температуре $+30{ }^{\circ} \mathrm{C}$, при коэффициенте температурного расширения газобетонной кладки 8·10-6 град-1 и изменении температуры от +30 до $-20{ }^{\circ} \mathrm{C}$, т. е. $=50{ }^{\circ} \mathrm{C}$, полная деформация сжатия составит 3,2 мм. А летом, при нагреве до $+80{ }^{\circ} \mathrm{C}[1]$, деформация расширения составит 3,2 мм. 
Зимой деформация сжатия штукатурного раствора (1:4) составит 0,55 мм/м, а полная деформация сжатия штукатурного покрытия стены длиной 8 м составит 4,4 мм. Летом полная деформация расширения штукатурного покрытия составит 4,4 мм. Деформации расширения или сжатия вызывают напряжения ( $\sigma)$ в кладке и штукатурном покрытии.

Разность деформаций, модулей упругости кладки и штукатурного покрытия является причиной деформаций сдвига в контактной зоне «кладка - штукатурное покрытие» (рис. 3д, 4а) и напряжений ( $\tau)$ (рис. 4б).

\begin{tabular}{|c|c|c|c|}
\hline$y$ & $z$ \\
\hline a & 6 & В \\
\hline
\end{tabular}

Рисунок 4. Аеформации (а), напряжения в контактной зоне (б) и развитие магистральной трещины (в)

Атмосферная влага, проникая в трещины штукатурного покрытия, а через них в контактную зону, создает расклинивающее давление в вершине трещины. Из-за этого в этой зоне возникают растягивающие напряжения (рис. 5a), что приводит к дальнейшему развитию магистральных трещин в штукатурном покрытии и контактной зоне его с кладкой.
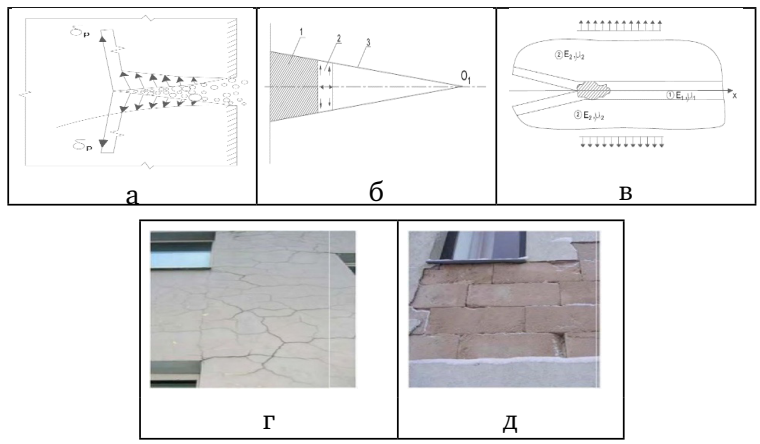

Рисунок 5. Развитие магистральной трещины в контактной зоне из-за воздействия воды (а), мьда (б, в) и разрушение штукатурного покрытия (г, А) 
При минусовых температурах в зимнее время развитие трещин ускоряется из-за превращения воды в лед (рис. 5б, 5в), что в конечном итоге приводит к разрушению штукатурного покрытия и стеновой конструкции (рис. 5г, 5д).

Для того чтобы предотвратить разрушение штукатурного покрытия, необходимо рассчитывать величины его физико-механических характеристик (прочность при сжатии и изгибе, модуль упругости и др.) с учетом напряжений в нем и контактной зоне с кладкой, возникающих при твердении раствора и деформации стеновой конструкции. При этом предельно допустимые напряжения должны быть меньше разрушающих. Подбор состава раствора необходимо вести и с учетом процессов, протекающих при нанесении и твердении раствора на кладку. Необходимо увеличить водоудерживающую способность смеси, уменьшить усадку штукатурного покрытия при твердении, уменьшить количество трещин, возникающих при твердении, и предотвратить или замедлить их развитие.

Целью исследований явилось получение штукатурных растворов с высокой трещиностойкостью при обеспечении требований нормативных документов по средней плотности, прочности при сжатии и изгибе и других параметрах.

В эксперименте для уменьшения усадки штукатурного покрытия и предотвращения появления усадочных трещин использовали мелкий заполнитель и наполнитель с низким модулем упругости (вермикулитовый и из боя газобетона) - смесь № 1, из отходов камнепиления известняка и перлитового песка - смесь № 2. Полученный эффект усиливали введением редиспергируемого полимерного порошка Winnapas 5043 Н и эфиров целлюлозы TyloseMBZ 15009. Их наличие также позволит уменьшить модуль упругости штукатурного покрытия и напряжения в нем и контактной зоне, а при добавлении полимерной фибры будет уменьшена скорость развития трещин, что позволит повысить долговечность покрытия и стеновой конструкции.

Для оптимизации рецептурно-технологических параметров использовали пятифакторный эксперимент со следующими варьируемыми факторами в таблице 1. 
Аиапазон варьирования факторов

\begin{tabular}{|c|c|c|c|c|c|c|}
\hline \multirow[t]{2}{*}{ Вид смеси } & \multirow[t]{2}{*}{$\begin{array}{c}\text { Диапазон } \\
\text { варьиро- } \\
\text { вания }\end{array}$} & $\begin{array}{c}\text { Расход } \\
\text { вяжущего, } \\
\text { кг } / \mathrm{M}^{3}\end{array}$ & $\begin{array}{c}\text { Расход за- } \\
\text { полнителя } \\
\text { и наполни- } \\
\text { теля, } \\
\text { м }^{3} / \mathbf{M}^{3}\end{array}$ & 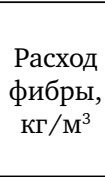 & $\begin{array}{c}\text { Расход } \\
\text { порошка } \\
\text { Winnapas } \\
5043 \text { H, \% }\end{array}$ & $\begin{array}{c}\text { Расход } \\
\text { Туlose } \\
\text { MBZ } \\
15009, \%\end{array}$ \\
\hline & & $\mathrm{X} 1$ & $\mathrm{X} 2$ & $\mathrm{X} 3$ & $\mathrm{X} 4$ & $\mathrm{X} 5$ \\
\hline \multirow{3}{*}{ 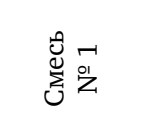 } & 1 & 500 & $1,05 / 1$ & 1,2 & 5 & 0,5 \\
\hline & 0 & 400 & $1,05 / 1$ & 0,9 & 3 & 0,3 \\
\hline & -1 & 300 & $1,05 / 1$ & 0,6 & 1 & 0,1 \\
\hline \multirow{3}{*}{ 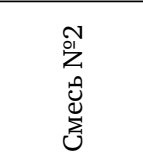 } & 1 & 400 & $1,05 / 1$ & 1,2 & 5 & 0,5 \\
\hline & 0 & 300 & $1,05 / 1$ & 0,9 & 3 & 0,3 \\
\hline & -1 & 200 & $1,05 / 1$ & 0,6 & 1 & 0,1 \\
\hline
\end{tabular}

Для определения свойств штукатурного раствора изготавливали образцы балочки размером 40×40х160 мм на газобетонном основании. Режим твердения воздушно-сухой, моделирующий работу штукатурного покрытия в реальных условиях.

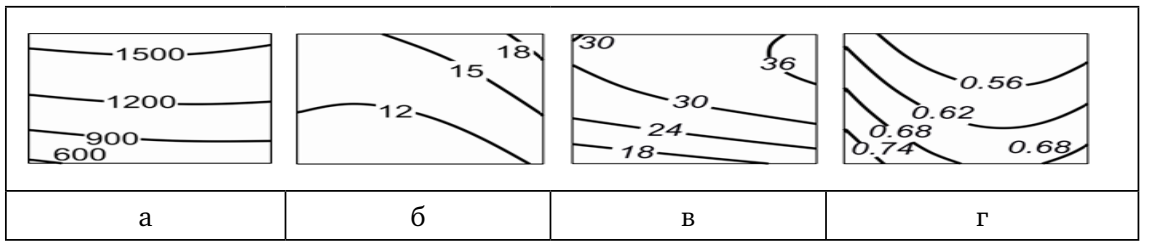

Рисунок 6. СреАняя плотность (а), прочность при изгибе (б) и сжатии (в), коэффициент трещиностойкости (г) состава № 1

После 28 суток твердения определяли: прочность при сжатии и изгибе, среднюю плотность и др. Трещиностойкость определяли визуально по наличию трещин в покрытии и рассчитывая коэффициент трещиностойкости как отношение прочности при изгибе к прочности при сжатии.

В результате получены штукатурные растворы со следующими свойствами. Состав № 1: средняя плотность 600-1500 кг/м ${ }^{3}$, проч-


$\mathrm{cm}^{2}$, коэффициент трещиностойкости 0,56-0,74 (рис. 6а-г). 
Состав № 2: средняя плотность 700-1100 кг/м³

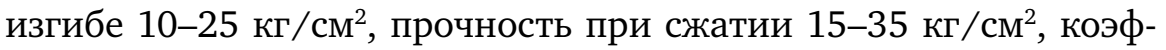
фициент трещиностойкости 0,25-1 (рис. 7а-г).

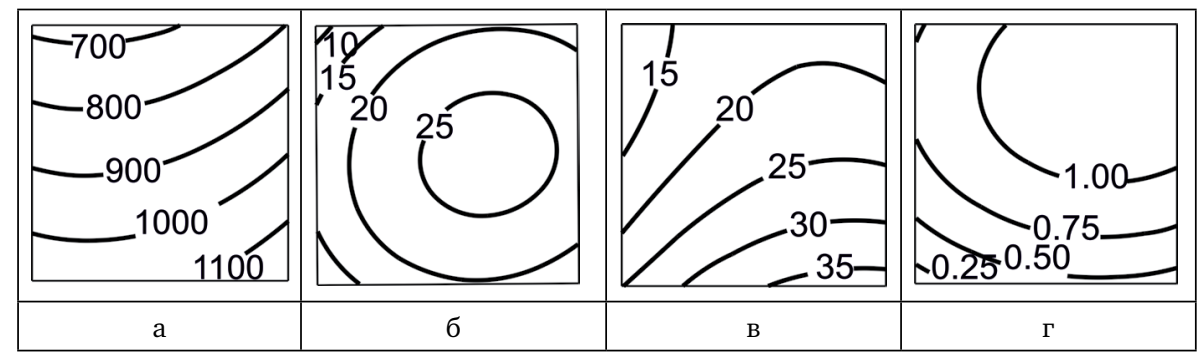

Рисунок 7. Среаняя плотность (а), прочность при изгибе (б), прочность при сжатии (в), коэффициент трещиностойкости (г) состава № 2

Полученные штукатурные растворы удовлетворяют требованиям нормативных документов по средней плотности

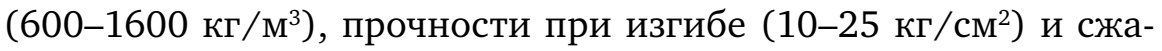
тии (25-50 кг/ $\left.\mathrm{cm}^{2}\right)$. Штукатурное покрытие обладает высокой трещиностойкостью, коэффициент трещиностойкости составляет 0,25-1, тогда как трещиностойкой считается штукатурка с показателем $>0,26$.

\section{ЗАКАЮЧЕНИЕ}

Увеличение доли высотного строительства и широкое применение новых стеновых материалов требует разработки научных основ проектирования составов штукатурных растворов. Для этого проведен анализ процессов, протекающих в штукатурном покрытии при его нанесении и твердении, рассмотрен механизм разрушения системы «кладка - штукатурное покрытие», приведены формулы для расчета напряжений. Сформулированы принципы и критерии, при которых будет обеспечена долговечность штукатурного покрытия и стеновой конструкции, рекомендованы составляющие и подобраны составы материала. 


\section{СПИСОК ИСПОАЬЗОВАННЫХ ИСТОЧНИКОВ}

1. Галкин, С. Л. Применение ячеистобетонных изделий. Теория и практика / С. Л. Галкин, Н. П. Сажнев, Л. В. Соколовский и др. - Минск : НП ООО «Стринко», 2006. -458 c.

2. Кнатько, M. В. К вопросу о долговечности и энергоэффективности современных ограждающих стеновых конструкций жилых, административных и производственных зданий / М. В. Кнатько, М. Н. Ефименко, А. С. Горшков // Инженерно-строительный журнал. - 2008. - № 2. - С. 50-53.

3. Блази, В. Справочник проектировщика. Строительная физика / В. Блази. - М. : Техносфера, 2005. - 536 с.

4. Сажнева, Н. Н. Защитные системы для отделки ячеистого бетона пониженной плотности / Н. Н. Сажнева, Н. П. Сажнев, Е. А. Урецкая // Строительные материалы. 2009. - № 1. - С. 17-19.

5. Паплавскис, Я. Требования к штукатурным составам для наружной отделки стен из ячеистых бетонов. Проблемы эксплуатационной надежности наружных стен на основе автоклавных газобетонных блоков и возможности их защиты от увлажнения / Я. Паплавскис, А. Фрош // Штукатурные составы для наружной отделки стен из газобетона: мат-лы сем. / Политехнический ун-т ; под ред. Н. И. Ватина. - Санкт-Петербург, 2010. - С.10-15.

6. Емельянов, А. А. Повреждения наружных панелей жилых полносборных зданий при температурных деформациях по данным натурных исследований / А. А. Емельянов / / Анализ причин аварий и повреждений строительных конструкций / Издательство литературы по строительству ; под ред. А. А. Шишкина. - № 2. - Москва, 1964. - С.153-177.

7. Волдржих, Ф. Деформационные швы в конструкциях наземных зданий / Ф. Волдржих. - М. : Стройиздат, 1978. - С. 209-221.

8. Рунова, Р. Ф. Основи виробництва стінових та оздоблювальних матеріалів / Р. Ф. Рунова, Л. О. Шейнич, О. Г. Гелевера, В. І. Гоц. - Київ : КНУБА, 2001. - 354 с. 


\section{REFERENCES}

1. Galkin S. L., Sazhnev N. P., Sokolovskiy L. V., others. Primeneniye yacheistobetonnykh izdeliy. Teoriya i praktika [The use of cellular concrete products. Theory and practice]. Minsk: NP Strinko LLC. 2006. 458 p. (rus)

2. Knat'ko M. V., Efimenko M. N., Gorshkov A. S. Engineering and Construction Journal. 2008. No 2. pp. 50-53. (rus)

3. Blazi V. Spravochnik proyektirovshchika. Stroitelnaya fizika [Designer's handbook. Construction Physics] Moscow: Technosphere. 2005. 536 p. (rus)

4. Sazhneva N. N., Sazhnev N. P., Uretskaya E. A. Building materials. 2009. No 1. pp. 17-19. (rus)

5. Paplavskis J., Frosh A. Plaster compositions for the exterior decoration of aerated concrete walls. Workshop materials. Saint Petersburg. 2010. pp.10-15. (rus)

6. Emelyanov A. A. Analysis of the causes of accidents and damage to building structures. 1964. No 2. pp. 153-177. (rus)

7. Voldrzhikh F. Deformatsionnyye shvy $v$ konstruktsiyakh nazemnykh zdaniy [Expansion joints in the construction of aboveground buildings]. Moscow: Stroyizdat. 1978. 224 p. (rus)

8. Runova R. F., Sheinich L. O., Gelevera O. G., Gots V. I. Osnovy vyrobnytstva stinovykh ta ozdoblyuval'nykh materialiv [Fundamentals of production of wall and decoration materials]. Kiev: KNUBA. 2001. 354 p. (ukr)

Received: 14.11.2019 